\title{
USE OF NANOPOROUS CERAMIC MEMBRANES FOR CARBON DIOXIDE SEPARATION
}

\author{
M.N. KAJAMA, N.C. NWOGU \& E. GOBINA \\ Centre for Process Integration and Membrane Technology, (CPIMT), School of Engineering, \\ The Robert Gordon University, Aberdeen, UK.
}

\begin{abstract}
Natural gas processes accounts for about 5.3 billion tonnes per year of carbon dioxide $\left(\mathrm{CO}_{2}\right)$ emission to the atmosphere. At this rate of emission, the expectation will drastically rise if not curtailed. In order to achieve this, a cost-effective and environmental friendly technology is required. In recent times, membrane technology has been widely applied for $\mathrm{CO}_{2}$ removal from raw natural gas components. This article examines $\mathrm{CO}_{2}$ separation from natural gas, mainly methane $\left(\mathrm{CH}_{4}\right)$, through a mesoporous composite membrane. A laboratory scale tubular silica membrane with a permeable length of $348 \mathrm{~mm}$, I.D and O.D of 7 and $10 \mathrm{~mm}$, respectively, was used in this experiment. Scanning electron microscopy (SEM) was used to analyze the morphology of the membrane. Single gas permeation of helium (He), $\mathrm{CH}_{4}$, nitrogen $\left(\mathrm{N}_{2}\right)$, argon $(\mathrm{Ar})$ and $\mathrm{CO}_{2}$ were determined at permeation temperature range between 25 and $100^{\circ} \mathrm{C}$ and feed gauge pressure of 0.05 to $5.0 \mathrm{barg}$. Before silica modification, He recorded the highest flow rate $(0.3745 \mathrm{l} / \mathrm{min})$ while $\mathrm{CO}_{2}$ recorded the least flow rate $(0.1351 \mathrm{l} / \mathrm{min})$ at $0.4 \mathrm{barg}$ and $25^{\circ} \mathrm{C}$. After silica modification, $\mathrm{CO}_{2}$ flow enhances significantly $(3.1180 \mathrm{l} / \mathrm{min}$ at $1.0 \mathrm{barg})$ compared to $\mathrm{CH}_{4}(2.1200 \mathrm{l} / \mathrm{min}$ at the same gauge pressure) due to the influence of surface flow mechanism. Temperature variation described the applicability of Knudsen diffusion for He. A combination of viscous, surface and Knudsen diffusion transport mechanisms were obtained throughout the experiment. Membrane thickness was also calculated to be $2.5 \times 10^{-4} \mathrm{~m}$.

Keywords: Carbon dioxide removal, dip-coating, gas permeation, nanoporous ceramic membranes, natural gas separation, permeation temperature, surface flow.
\end{abstract}

\section{INTRODUCTION}

The world population is expected to increase from 7.16 billion in 2014 [1] to 9.2 billion by 2050 [2]. Energy consumption is also expected to rise from 15 million MW per year to 40 million MW by 2050 [2]. The use of fossil fuels continue to dominate the world's energy demand, with the share of natural gas alone being approximately $23.5 \%$, which significantly contributes to the global climate change due to the related emissions of greenhouse gases, such as carbon dioxide $\left(\mathrm{CO}_{2}\right)$, methane $\left(\mathrm{CH}_{4}\right)$, carbon monoxide, nitrous oxide among others $[3,4]$. According to the Intergovernmental Panel on Climate Change (IPCC) Fourth Assessment Report, natural gas processing emitted about 5.3 billion tons of $\mathrm{CO}_{2}$ in 2004, while coal and oil emitted 10.6 and 10.2 billion tons, respectively [5]. In recent years, some carbon reduction policies were introduced in order to mitigate the increase of $\mathrm{CO}_{2}$ emission globally [6]. From an environmental point of view, it is imperative to separate $\mathrm{CO}_{2}$ from natural gas in order to safeguard our environment. A number of techniques tend to emerge as a substitute to this application, such as absorption, adsorption, and membrane processes [2].

Membrane processes have recently emerged as the state-of-the-art technology for such application. Among the merits of membrane technology for $\mathrm{CO}_{2}$ separation is that, it requires low energy and is attracts $\mathrm{CO}_{2}$ by chemical modification of the pore walls using other materials, such as silica [7]. Membrane technique was applied five decades ago for desalination purposes [2] and natural gas processing [8]. Polymeric membranes, such as 
hollow fibre composite membranes, have been used. The investigation disclosed that polymeric membranes are limited for some applications. Therefore, ceramic membranes substituted polymeric membranes as they are chemically resistant and thermally stable. Membranes are basically barriers that are selective to one component and reject/hinder others. Their performance is dictated by membrane strength, permeability and selectivity [8]. Membranes can be classified into inorganic and organic systems. The organic ones are further divided into biological and polymeric constituents, while inorganic membranes can be divided into metallic and ceramic (porous and non-porous) membranes [8]. According to the International Union of Pure and Applied Chemistry (IUPAC), porous membranes are classified as; micropores $0.5-2 \mathrm{~nm}$, mesopores $2-50 \mathrm{~nm}$ and macropores $>50 \mathrm{~nm}$ $[9,10]$. In recent times, membranes were fabricated from polymeric materials in the industry but these have limited the application owing to being less resistant to chemical attacks and high temperatures. It is for these reasons that inorganic membrane technology is receiving an ever-increasing attention [11]. Inorganic membranes are commonly made from ceramic, metal oxide or sintered metal, palladium metal, zeolite among others, which are applied in the laboratory scale experiment [12]. Sol-gel method is widely applied as the preferred preparation method for inorganic membranes. This method is being used to obtain microporous ceramic membranes, for example, by depositing silica layers on ceramic supports. These ceramic supports can either be alumina or porous Vycor glass $[13,14]$.

Some literature $[15,16]$ describes the mass transport through membranes. The so-called Knudsen number is used to classify gas flow in a porous media, which is written as [16]:

$$
K_{n}=\frac{\lambda}{d_{p}}
$$

where $\lambda$ is the mean free path of gas molecules, and $d_{p}$ is the pore diameter.

Also mean free path can be defined as the distance traversed by a gas molecule from one collision to the other and is given as [16,17]:

$$
\lambda=\frac{R T}{\sqrt{2} \pi d^{2} N_{A} P}
$$

where $N_{A}$ Avogadro's number (mol), $P$ pressure (pa), $d$ diameter (m), $R$ gas constant $(8.314$ $\mathrm{J} . \mathrm{K}^{-1} \cdot \mathrm{mol}^{-1}$ ) and $T$ is the permeation temperature $(\mathrm{K})$.

Gas transport through porous membranes are influenced by viscous flow, Knudsen diffusion, surface flow, multi-layer diffusion, capillary condensation, molecular sieving and solution-diffusion transport mechanisms $[15,18,19]$.

Viscous flow is determined if the mean free path is smaller than the pore diameter, the flow characteristics are determined primarily by collisions among the molecules and can be written as [16]:

$$
P_{v}=\left(\frac{\varepsilon r^{2} p_{a v} \Delta p}{8 \pi \mu R T L}\right)
$$

where $\varepsilon$ is the porosity of the membrane, $r$ is the mean pore radius $(\mathrm{m}), P_{a v}=(\mathrm{p} 1+\mathrm{p} 2) / 2$ is the average pressure (Pa), $\Delta P$ is the pressure difference $(\mathrm{Pa}), \mu$ is the viscosity (Pa-s) and $L$ is the thickness of the membrane $(\mathrm{m})$. 
Knudsen diffusion occurs if the mean free path is effectively larger than the pore diameter. If the collisions among the permeating molecules and the pore wall of the membrane are the main transport mechanism, the separation is based on molecular weight difference $[15,16,19]$. Thus, Knudsen permeance states that the permeation flux is proportional to the inverse square root of both molecular weights of gases and temperature, which can subsequently be written as:

$$
P_{k n}=\left(\frac{\varepsilon 8 r_{p} \Delta p}{3 \pi L(2 \pi R T M)^{0.5}}\right)
$$

where $\tau$ is the tortuosity that describes the geometry and transport properties of porous media and $M$ is the molecular weight of the diffusing gas $(\mathrm{g} / \mathrm{mol})$.

However, if the mean free path of the gas molecules is equal to the pore diameter, then the flow is governed by the combination of both mechanisms (i.e. Eqns 3 and 4), which is written as:

$$
P_{t}=\frac{\varepsilon}{\pi L}\left(\frac{r^{2} P_{a v} \Delta p}{8 \mu R T}\right)+\left(\frac{8 r_{p} \Delta p}{3(2 \pi R T M)^{0.5}}\right)
$$

where $P_{t}$ is the total permeance $\left(\mathrm{mol} \mathrm{m}^{-2} \mathrm{~s}^{-1} \mathrm{~Pa}^{-1}\right)$.

Equation (5) can be rewritten as:

$$
P_{t}=C_{1} P_{a v}+C_{2}
$$

where $C_{1}$ and $C_{2}$ constants representing viscous and Knudsen flow respectively.

Surface flow can occur in parallel with viscous Knudsen diffusion. It occurs if the diffusing molecules adsorbed on the pore walls of the membrane and migrates along the pore surface. Multi-layer diffusion occurs if the flow of gas molecules is adsorbed in the membrane at different number of layers. Gas mixture permeates through the pores of the membrane at a given pressure and temperature. Molecular sieving is used to separate gas molecules that differ in kinetic diameter. It enables the permeation of gases that have lower kinetic diameter to pass through the membrane "sieve" than the larger ones [15]. Solution-diffusion separation relies on the physical-chemical interaction of gases and the dense membrane that determine the amount of gas that can accumulate in the membrane matrix [18].

In this work, a defect-free tubular membrane consisting of a thin silica active layer was obtained from the repeat dip-coating method. The effects of temperature and feed pressure on permeate flux have been experimentally studied on single gases for natural gas separation.

\section{EXPERIMENTAL}

\subsection{Experimental and membrane preparation}

The experimental set-up used in this study is shown in Fig. 1. It consists of a stainless steel tubular membrane reactor cell. Graphite rings with an I.D and O.D of 10.2 and $24 \mathrm{~mm}$, respectively, was used at each end of the stainless steel reactor. Single gases, such as $\mathrm{He}, \mathrm{N}_{2}$, $\mathrm{CO}_{2}, \mathrm{CH}_{4}$ and $\mathrm{Ar}$, with a purity of $\geq 99.99 \%$ ) supplied by BOC (UK) were used. A digital flowmeter was used to measure the permeation rates at different pressure drop across the membrane. 
Membrane modification was achieved using the repeated dip-coating method. The solution was prepared by mixing $50 \mathrm{ml}$ of silicon elastomer $\left(\right.$ Sylgard $\left.^{\circledR}\right)$ and nine parts of isopentane contained in a glass tube to obtain a clear and colourless solution. A curing agent (Sylgard ${ }^{\circledR}$ ) equivalent to one-tenth of the elastomer was added and the resulting solution was mixed at room temperature. The solution was then allowed to age for $30 \mathrm{~min}$ after which the ceramic support was immersed for $30 \mathrm{~min}$. The membrane was then oven dried at $65^{\circ} \mathrm{C}$ for $24 \mathrm{~h}$ to form an ultra-thin layer on the support. The same procedure was repeated for subsequent coatings. Up to seven dips were prepared and evaluated at room temperature in this experiment $[20,21]$.

\subsection{Membrane characterization}

The tubular commercial ceramic support consists of $77 \%$ alumina and $23 \% \mathrm{TiO}_{2}$ with a nominal pore size of $15 \mathrm{~nm}$. The membrane has a permeable length of $348 \mathrm{~mm}$ with I.D and O.D of 7 and $10 \mathrm{~mm}$, respectively. The surface and cross-sectional morphologies of the support and membrane were analysed by scanning electron microscopy (SEM) (Zeiss EVO LS10). The membrane was found to be defect-free. Figures 2 and 3 show a SEM image of the inside and outside surface of the support before modification. The SEM of the cross-section of the membrane is shown in Fig. 4. Membrane thickness was calculated using Eqn (7) from the literature [22]:

$$
L=\frac{W_{2}-W_{1}}{A \rho(1-\varepsilon)}
$$

where $L$ is the membrane's thickness, $W_{1}$ is the weight of the alumina support before coating, $W_{2}$ is the total weight of the support and the membrane, $A$ is the membrane's area, $\rho$ is the theoretical density of alumina $\left(3.95 \times 10^{3} \mathrm{~kg} \cdot \mathrm{m}^{-3}\right)$ [23] and $\varepsilon$ is the porosity of the membrane $(45 \%)$.

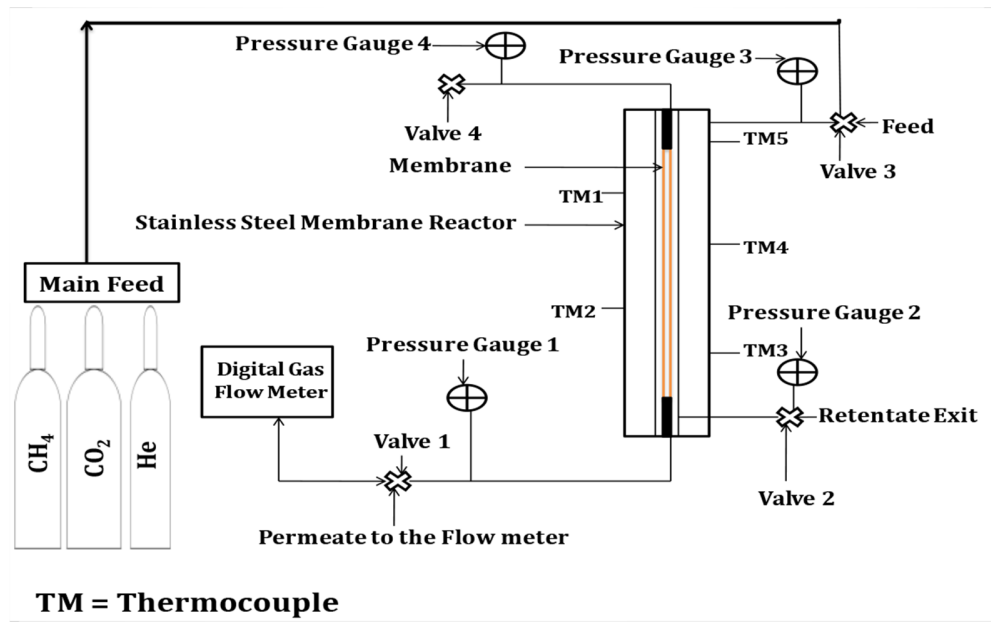

Figure 1: Schematic diagram for the permeation test experiment. 


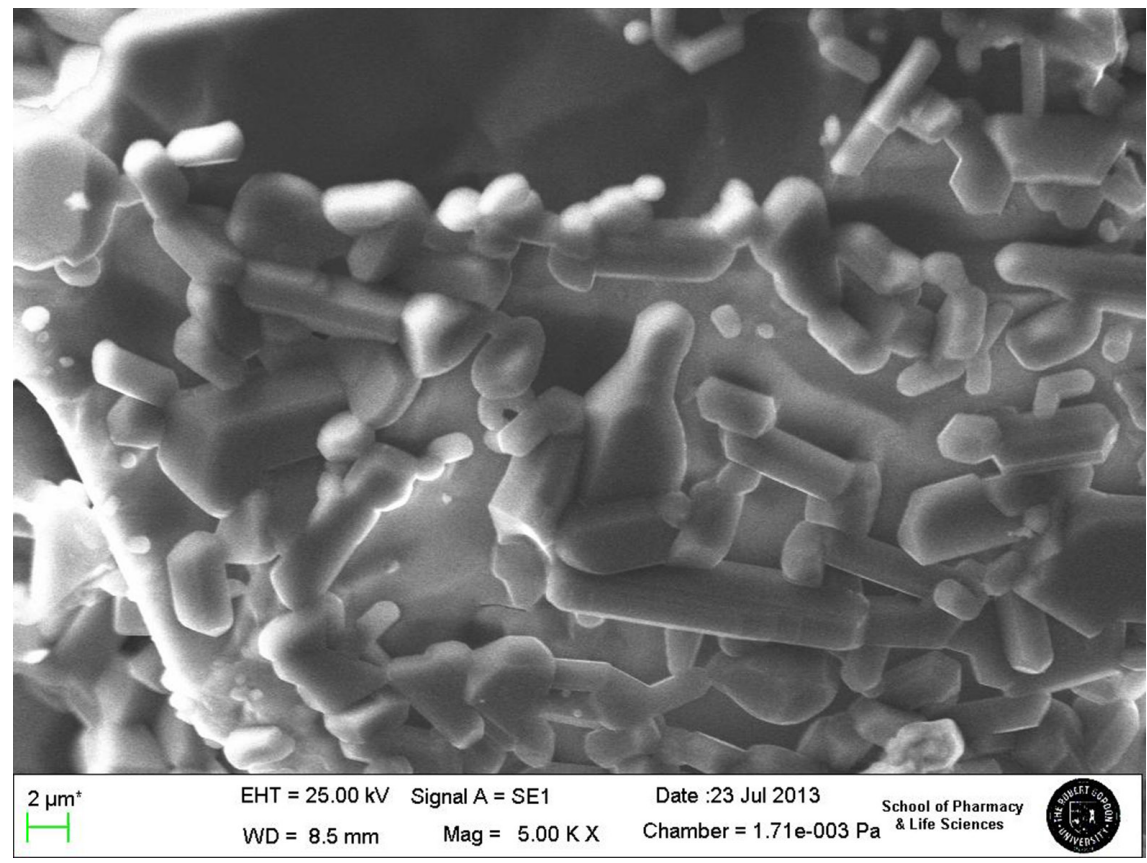

Figure 2: SEM image of the support inside surface.

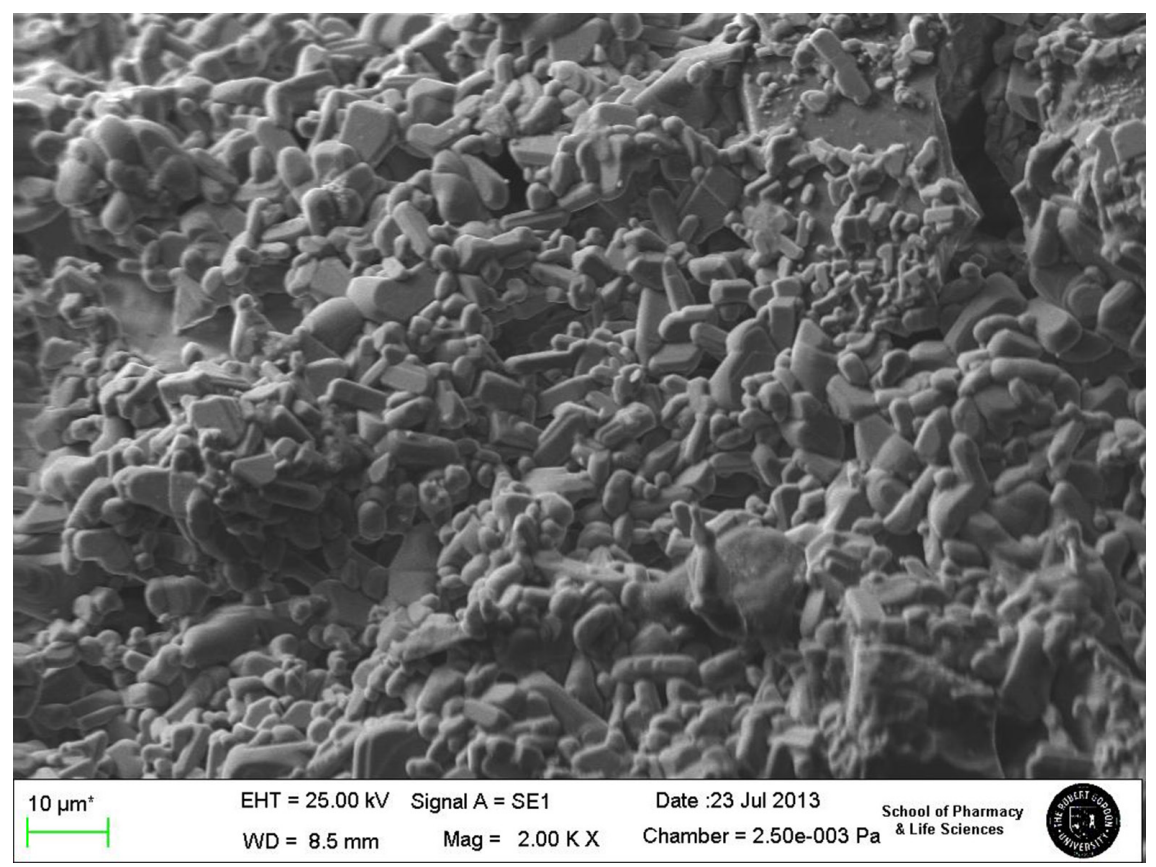

Figure 3: SEM image of the support outside surface. 


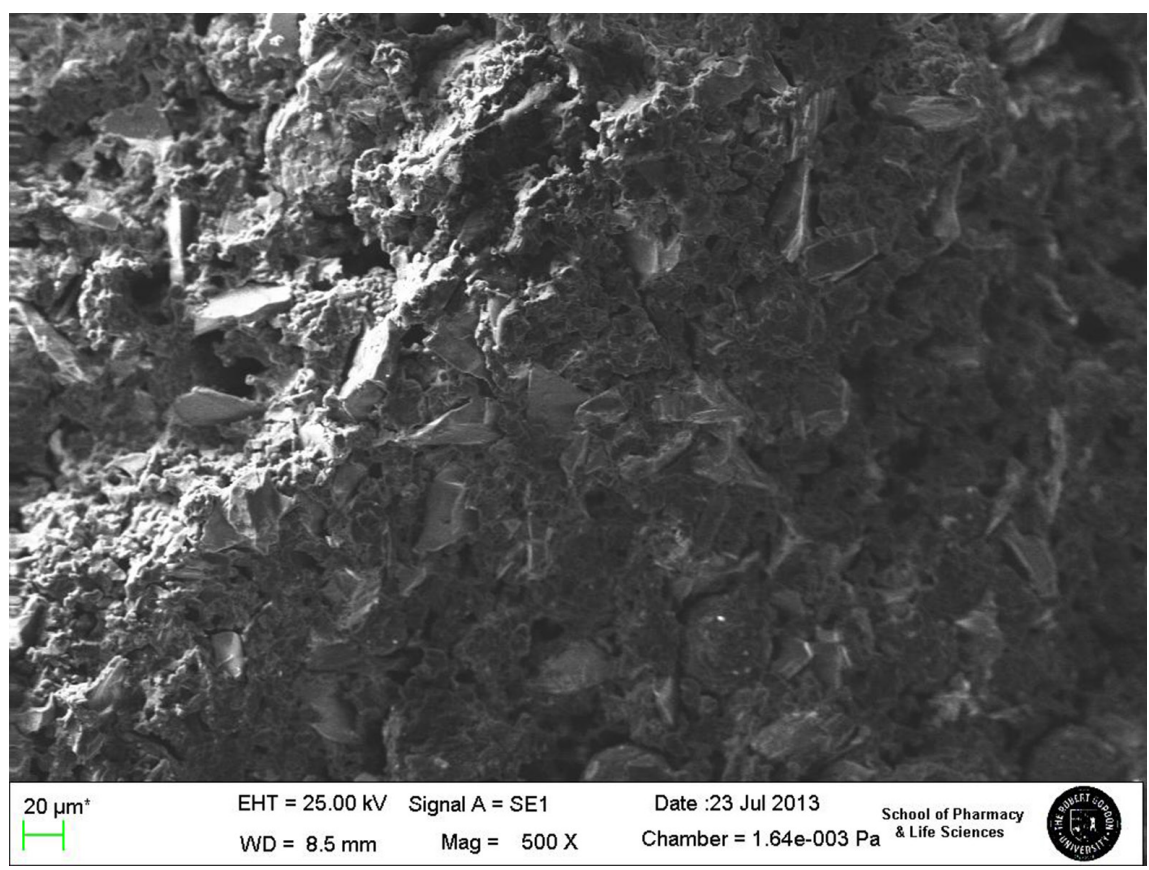

Figure 4: SEM image of the membrane's cross-sectional area.

\section{RESULTS AND DISCUSSION}

\subsection{Membrane thickness}

Figures $5(\mathrm{a}, \mathrm{b})$ and $6(\mathrm{a}, \mathrm{b})$ show the EDXA (Oxford Instruments INCA System) and the SEM images of the outer and inner surface of the silica membrane. It is obvious from the image that some amount of silica has been adsorbed by the membrane during the dip-coating process. Figure 7 shows the increments in membrane thickness as a function of number of dips. The thickness per dip decreases as the number of dips increases, which is what was expected. Generally, the total thickness obtained was $2.5 \times 10^{-4} \mathrm{~m}$ and the exposure time per dip was $30 \mathrm{~min}$.

\subsection{Gas permeation}

Different gas permeation and feed pressure relationship were obtained from the support and the membrane at temperatures up to $100^{\circ} \mathrm{C}$. Figure 8 show a typical example of single gases permeation behaviour for the unmodified membrane for fully opened retentate at $25^{\circ} \mathrm{C}$. The feed pressure tested were between 0.05 and 0.40 bar, and it was found that the permeate flux increases linearly with increasing feed pressure. It can be seen that He recorded the highest permeate flux while $\mathrm{CO}_{2}$ recorded the least permeate flux. In that case, an unmodified support does not support $\mathrm{CO}_{2}$ removal from natural gas process. Figure 9 depicts the relationship between $\mathrm{CH}_{4}$ and $\mathrm{CO}_{2}$ separation against feed gauge pressure at $25^{\circ} \mathrm{C}$ for fully opened retentate. It is obvious that $\mathrm{CO}_{2}$ has been positively separated from $\mathrm{CH}_{4}$ after silica modification 


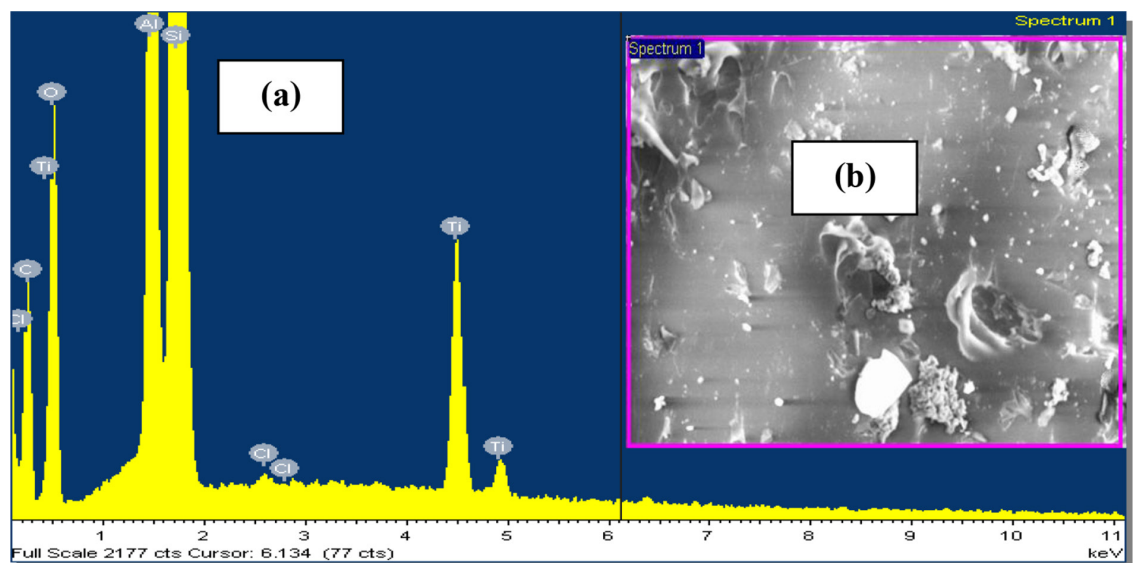

Figure 5: SEM and EDXA image of the membrane's outside surface after modification.

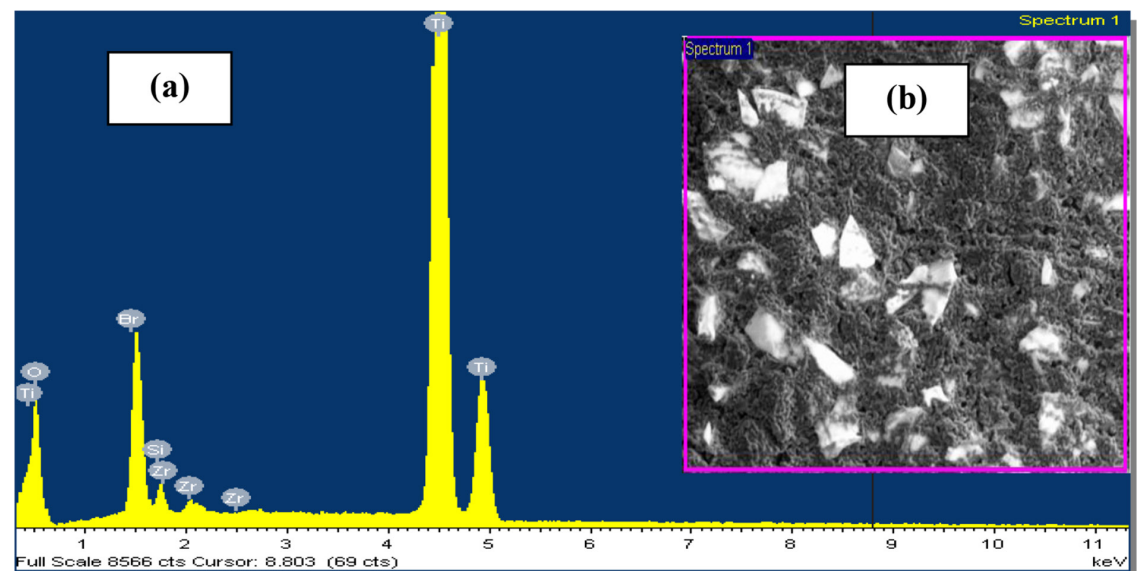

Figure 6: SEM and EDXA image of the membrane's inside surface after modification.

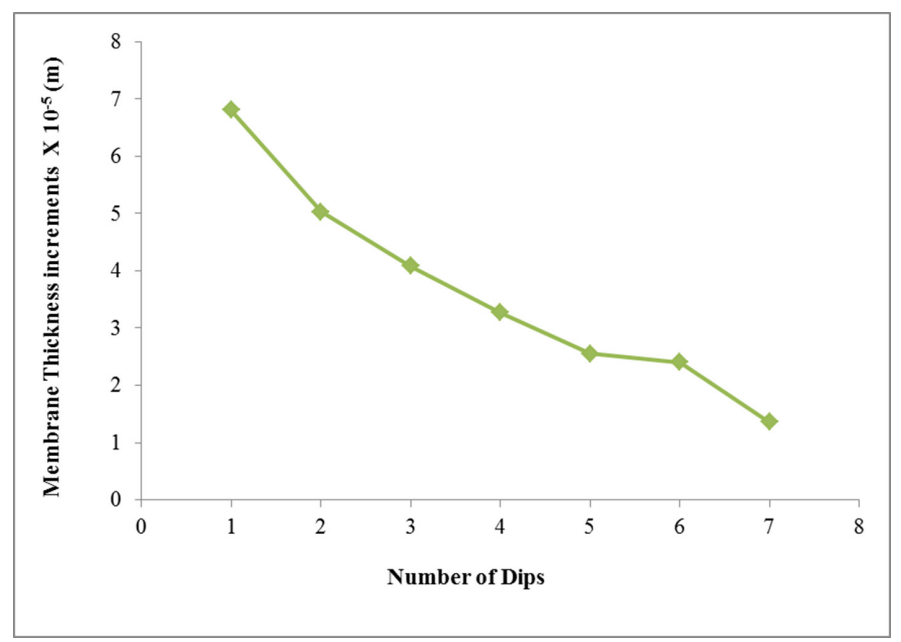

Figure 7: Membrane thickness against number of dips. 


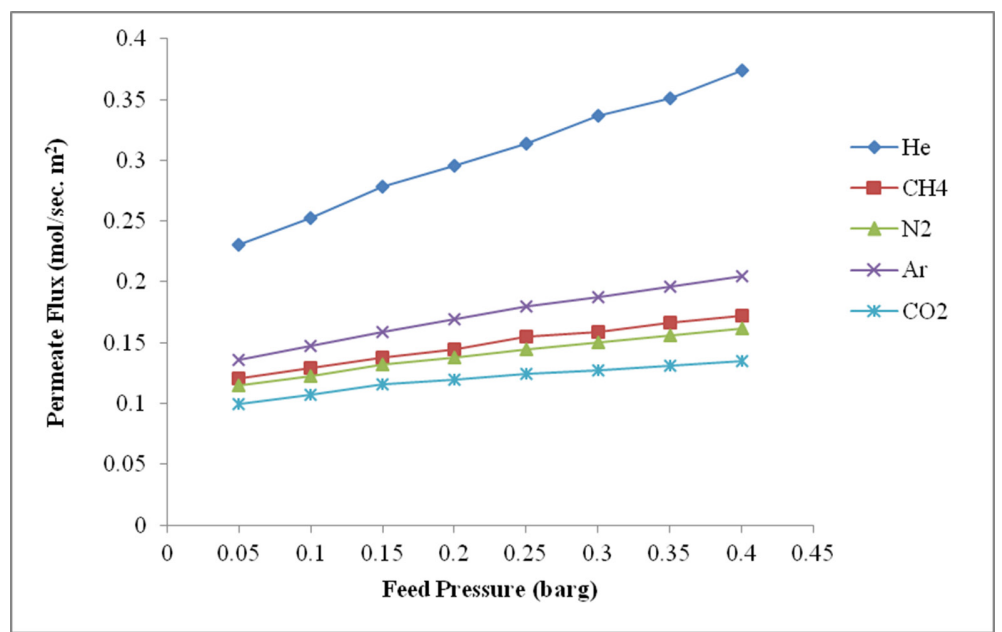

Figure 8: Gas permeates flux for unmodified membrane against feed pressure at $25^{\circ} \mathrm{C}$ (fully opened retentate)

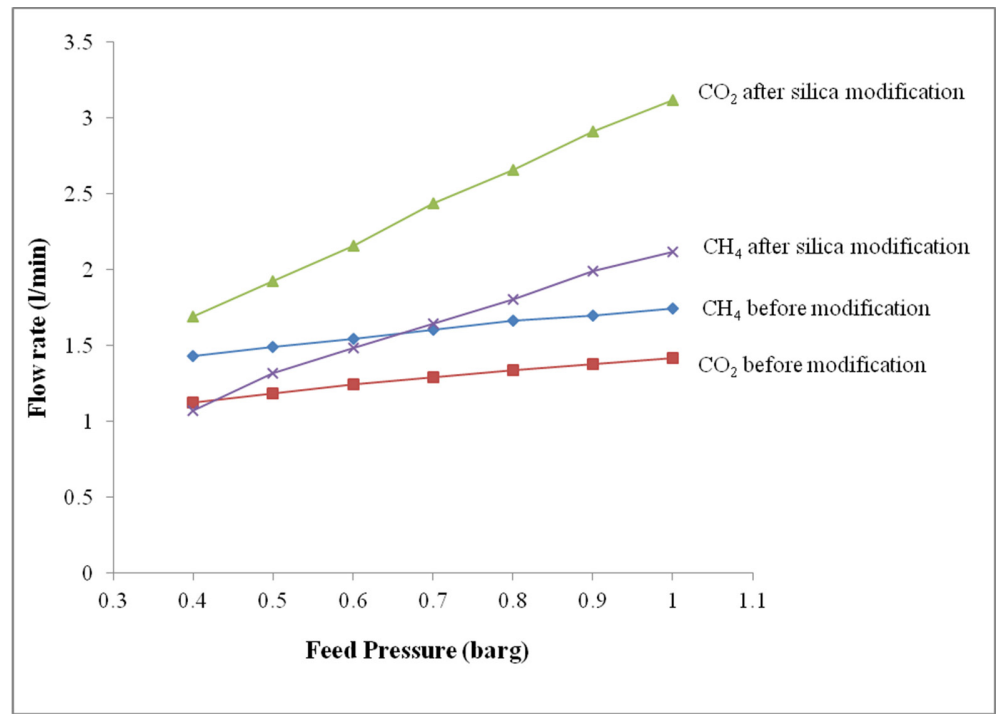

Figure 9: Flow rate of $\mathrm{CO}_{2}$ separation against feed pressure at $25^{\circ} \mathrm{C}$.

via the repeat dip-coating method. This indicates that silica membranes offers good separation performance for the removal of $\mathrm{CO}_{2}$ from natural gas, mainly methane.

Figure 10 depicts the relationship between $\mathrm{CO}_{2}$ flow rates against feed pressure before and after silica modification at $25^{\circ} \mathrm{C}$ for fully opened retentate. It is obvious that $\mathrm{CO}_{2}$ permeation increased after silica modification, which clearly indicates that higher $\mathrm{CO}_{2}$ transport is achieved through the repeat dip-coated membrane corroborating literature [15]. A comparison of the gas transport for both methane and $\mathrm{CO}_{2}$ confirms this point as shown in Fig. 11.

According to Eqn (6), the plots of permeance of $\mathrm{CO}_{2}$ and $\mathrm{CH}_{4}$ against average pressure are illustrated in Fig. 11. It can be seen that a good linear relationship exist between $P_{t}$ and $P_{a v}$ 


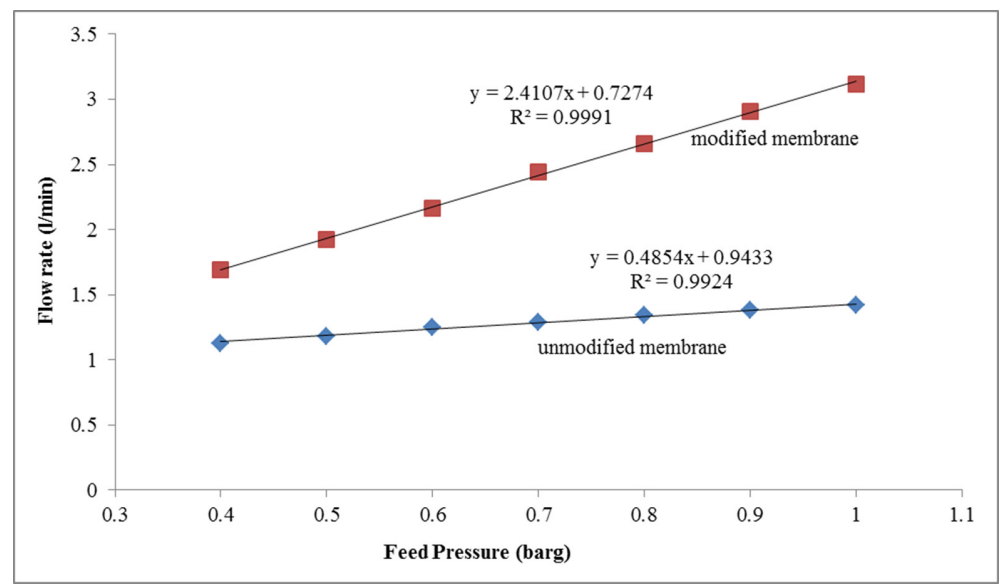

Figure 10: $\mathrm{CO}_{2}$ flow rate depending on feed pressure before and after modification at $25^{\circ} \mathrm{C}$.

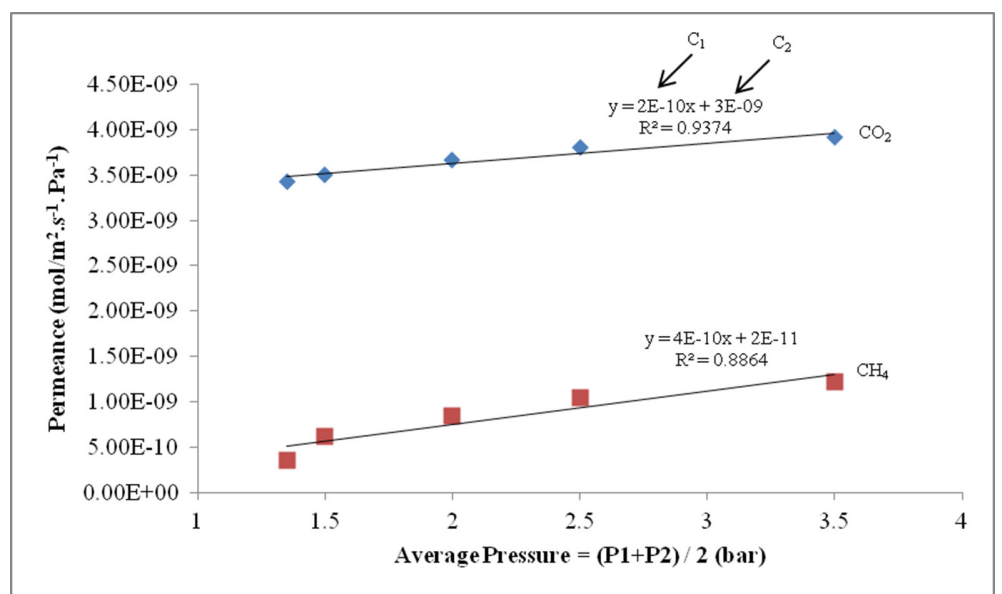

Figure 11: Permeance of $\mathrm{CO}_{2}$ and $\mathrm{CH}_{4}$ against average pressure after silica modification at $25^{\circ} \mathrm{C}$.

for the silica membrane at room temperature. The values of $C_{1}$ and $C_{2}$ are obtained by fitting the plots into straight line shown in Fig. 11. It is suggested that an adsorptive transport contribution occurred due to the interaction between gas molecules and the wall of the membrane's pore. $\mathrm{CO}_{2}$ is known to strongly adsorb on the pore walls of silica membranes, resulting in surface flow. It is suggested that interaction between pore wall and $\mathrm{CO}_{2}$ can be improved by subsequent chemical modification of the pore wall with other materials, which will result in an increased surface flow as a transport mechanism [24]. Therefore, Eqn (6) becomes:

$$
P_{t}=C_{1} P_{a v}+C_{2}+C_{3}
$$

where $C_{3}$ is constant, representing the contribution of adsorptive surface flow mechanism.

It can be seen in Fig. 12 that He permeate flux decreases with increasing temperature for fully closed retentate at different transmembrane pressures. These slopes also indicate that 


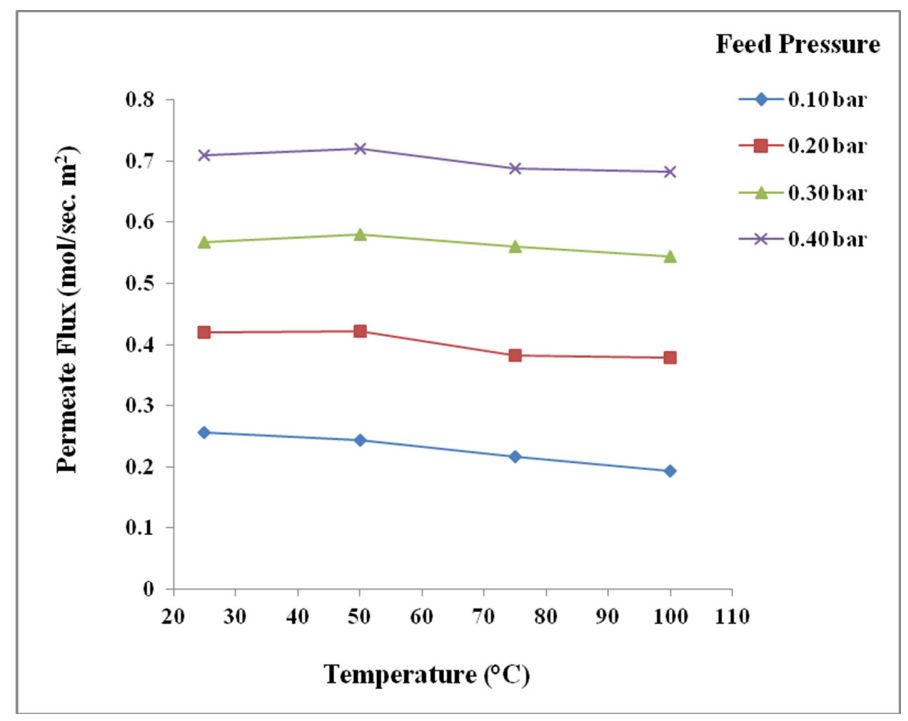

Figure 12: He permeation for modified membrane depending on temperature at different pressures.

gas permeability decreases with an increase in temperature, which is in line with Knudsen flow mechanism.

\section{CONCLUSIONS}

In this experiment, a laboratory scale tubular silica membrane was used. The influence of permeation temperature $\left(25\right.$ to $\left.100^{\circ} \mathrm{C}\right)$ and feed gauge pressure $(0.05$ to $5.0 \mathrm{barg})$ of $\mathrm{He}$, $\mathrm{CH}_{4}, \mathrm{~N}_{2}, \mathrm{Ar}$ and $\mathrm{CO}_{2}$ were examined from support and silica-modified membrane. The silica membrane offers better $\mathrm{CO}_{2}$ separation from $\mathrm{CH}_{4}$ with the retentate fully opened to $5.0 \mathrm{barg}$ at $25^{\circ} \mathrm{C}$ compared to unmodified membrane support. Surface flow mechanism is considered to be negligible for He permeate flux against the tested temperature $\left(25\right.$ to $\left.100{ }^{\circ} \mathrm{C}\right)$ at different feed gauge pressures $(0.10$ to $0.40 \mathrm{barg})$. The permeate flux drops from 0.2559 to 0.1936 between 25 to $100^{\circ} \mathrm{C}$ at $0.10 \mathrm{barg}$, whereas between 25 to $100^{\circ} \mathrm{C}$ at $0.40 \mathrm{barg}$, the permeate flux is almost independent of pressure. The influence of Knudsen diffusion, viscous flow and surface flow mechanisms were achieved based on the experimental results obtained.

\section{ACKNOWLEDGEMENTS}

The authors gratefully acknowledge Petroleum Technology Development Fund (PTDF) Nigeria for funding this research, and School of Pharmacy \& Life Sciences RGU Aberdeen for the SEM and EDXA results.

\section{REFERENCES}

[1] http://www.worldometers.info/world-population/wpc.php?utm_expid=4939992-7. scuhn054Q5WX vFD9uRG9Xw.2 (Accessed on 29/04/2014).

[2] Adewole, J.K., Ahmad, A.L., Ismail, S. \& Leo, C.P., Current challenges in membrane separation of $\mathrm{CO}_{2}$ from natural gas: A review. International Journal of Greenhouse Gas Control, 17, pp. 46-65, 2013.

http://dx.doi.org/10.1016/j.ijggc.2013.04.012 
[3] Rui, Z., Ji, H. \& Lin, Y.S., Modeling and analysis of ceramic-carbonate dual-phase membrane reactor for carbon dioxide reforming with methane. International Journal of Hydrogen Energy, 36(14), pp. 8292-8300, 2011. http://dx.doi.org/10.1016/j.ijhydene.2011.02.110

[4] Brunetti, A., Scura, F., Barbieri, G. \& Drioli, E., Membrane technologies for $\mathrm{CO}_{2}$ separation. Journal of Membrane Science, 359(1), pp. 115-125, 2010. http://dx.doi.org/10.1016/j.memsci.2009.11.040

[5] http://www.solarpowernotes.com/non-renewable-energy/natural-gas-energy.html (Accessed on 29/04/2014).

[6] International Energy Outlook 2013, http://www.iea.org/Textbase/npsum/WEO2013SUM.pdf

[7] Pejman, A.N., Akbar, B.A., Elham, J., Majid, P. \& Masoumeh, A.A., An optimum routine for surface modification of ceramic supports to facilitate deposition of defectfree overlaying micro and meso (nano) porous membrane. Iran. J. Chem. Eng., 30(3), pp. 63-73, 2011.

[8] Lu, G.Q., Diniz da Costa, J.C., Duke, M., Giessler, S., Socolow, R., Williams, R.H. \& Kreutz, T., Inorganic membranes for hydrogen production and purification: A critical review and perspective. Journal of Colloid and Interface Science, 314(2), pp. 589-603, 2007. http://dx.doi.org/10.1016/j.jcis.2007.05.067

[9] Zhang, L., Park, I.S., Shqau, K., Winston Ho, W.S. \& Verweij, H., Supported inorganic membranes. Promises \& Challenges. JOM, 61(4), pp. 61-71, 2009. http://dx.doi.org/10.1007/s11837-009-0054-2

[10] Ahmad, A.L. \& Mustafa, N.N.N., Sol-gel synthesized of nanocomposite palladium-alumina ceramic membrane for $\mathrm{H}_{2}$ permeability: Preparation and characterisation. International Journal of Hydrogen Energy, 32(12), pp. 2010-2021, 2007. http://dx.doi.org/10.1016/j.ijhydene.2006.08.046

[11] Adom, P.K., Bekoe, W., Amuakwa-Mensah, F., Mensah, J.T. \& Botchway, E., Carbon dioxide emissions, economic growth, industrial structure, and technical efficiency: Empirical evidence from Ghana, Senegal, and Morocco on the causal dynamics. Energy, 47(1), pp. 314-325, 2012. http://dx.doi.org/10.1016/j.energy.2012.09.025

[12] Othman, M.R., Mukhtar, H. \& Ahmad, A.L., Gas permeation characteristics across nano-porous inorganic membranes. IIUM Engineering Journal, 5(2), pp. 17-33, 2004.

[13] Anwu, Li., Hongbin, Z., Jinghua, GU. \& Guoxing, X., Preparation of $\gamma$ - $\mathrm{Al}_{2} \mathrm{O}_{3}$ composite membrane and examination of membrane defects. Science of China (Series B), $\mathbf{4 0}$, pp. 31-36, 1997. http://dx.doi.org/10.1007/BF02882185

[14] Lee, D. \& Oyama, S.T., Gas permeation characteristics of a hydrogen selective supported silica membrane. Journal of Membrane Science, 210(2), pp. 291-306, 2002. http://dx.doi.org/10.1016/S0376-7388(02)00389-7

[15] Ohwoka, A., Ogbuke, I. \& Gobina, E., Performance of pure and mixed gas transport in reconfigured hybrid inorganic membranes part 2. Membrane Technology, 2012(6), pp. 7-9, 2012. http://dx.doi.org/10.1016/S0958-2118(12)70126-X

[16] Wall, Y., Braun, G. \& Brunner, G., Gas transport through ceramic membranes under super-critical conditions. Desalination, 250(3), pp. 1056-1059, 2010. 
http://dx.doi.org/10.1016/j.desal.2009.09.107

[17] Mulder, M., Basic Principles of Membrane Technology, Second Edition, Centre of Membrane Science and Technology. Kluwer Academic Publishers, University of Twente, Enschede, The Netherlands, pp. 227, 1996.

[18] Scholes, C.A., Kentish, S.E. \& Stevens, G.W., Carbon dioxide separation through polymeric membrane systems for flue gas applications. Recent Patents on Chemical Engineering, 1(1), pp. 52-66, 2008.

http://dx.doi.org/10.2174/2211334710801010052

[19] Kim, Y.S., Kusakabe, K., Morooka, S. \& Yang, S.M., Preparation of microporous silica membranes for gas separation. Korean Journal of Chemical Engineering, 18(1), pp. 106-112, 2001.

http://dx.doi.org/10.1007/BF02707206

[20] Gobina, E., Apparatus and Methods for Separating Gases. United States Granted Patent No. US 7,048,778, May 23, 2006.

[21] Nwogu, N.C., Gobina, E. \& Kajama, M.N., Improved carbon dioxide capture using nanostructured ceramic membranes. Low Carbon Economy, 4(3), pp. 125-128, 2013. http://dx.doi.org/10.4236/lce.2013.43013

[22] Zhu, J., Fan, Y. \& Xu, N., Modified dip-coating method for preparation of pinhole-free ceramic membranes. Journal of Membrane Science, 367(1), pp. 14-20, 2011. http://dx.doi.org/10.1016/j.memsci.2010.10.024

[23] Jin, Z., Yiqun, F. \& Nanping, X., Preparation and characterization of alumina membranes on capillary supports: Effects of film-coating on crack-free membrane preparation. Chinese Journal of Chemical Engineering, 18(3), pp. 377-383, 2010. http://dx.doi.org/10.1016/S1004-9541(10)60234-0

[24] Keizer, K., Uhlhorn, R.J.R. \& Burggraaf, A.J. Gas separation mechanisms in microporous modified $\gamma-\mathrm{Al}_{2} \mathrm{O}_{3}$ membranes. Journal of Membrane Science, 39(3), pp. 285-300, 1988.

http://dx.doi.org/10.1016/S0376-7388(00)80935-7 